\title{
USE OF MODIFIED ALVARADO SCORE IN THE MANAGEMENT OF ACUTE APPENDICITIS
}

\author{
P. Naresh Kumar1 1 P. Karuppasamy²
}

${ }_{1}^{1}$ Associate Professor, Department of General Surgery, Sri Venkateshwaraa Medical College Hospital \& Research Centre, Ariyur, Pondicherry.

${ }^{2}$ Assistant Professor, Department of General Surgery, Sri Venkateshwaraa Medical College Hospital \& Research Centre, Ariyur, Pondicherry.

\section{ABSTRACT}

\section{BACKGROUND AND OBJECTIVES}

The aim of the study is to evaluate acute appendicitis using modified Alvarado scoring and reducing the number of negative appendicectomies. The patients with suspected clinical diagnosis were evaluated by modified Alvarado score and depending on the score treatment was done either observation or surgery. The accuracy of modified Alvarado scoring system in diagnosing acute appendicitis was assessed.

\section{METHODS}

Patients considered for the study were 65 who presented to Sri Venkateshwaraa Medical College, Ariyur, Pondicherry, between Jan 2015-Dec 2015 with suspected diagnosis of acute appendicitis by normal clinical assessment, all of whom were evaluated by modified Alvarado score. The total number of patients were 65, of which 39 were males in the age group between 10 and 60 years and 21 were females in the age group of 10 and 40 years and 6 children were less than 10 years. The modified Alvarado score is a modification of the original Alvarado scoring system (By Kalan et al, Ann R Coll Surg Engl 1994), where the left shift of neutrophil is omitted, as this is not available on a routine basis, is scored against a total of 9 . It is based on 3 symptoms, 3 signs and a laboratory investigation. ${ }^{1}$ Patients with score 7 to 9 underwent an appendicectomy, while those with a score of less than 7 were not considered for surgery.

\section{RESULTS}

A study of 65 cases of acute appendicitis admitted to Sri Venkateshwaraa Medical College, Ariyur, Pondicherry, between Jan 2015Dec 2015 was made adopting the Kalan's modification of Alvarado scoring system. The symptoms commonly found among the patients with acute appendicitis was pain abdomen (100\%) with a classical shift of pain from umbilicus to RIF (83\%), next observed were nausea and vomiting. While fever was seen in 54\% of cases, RIF tenderness was the commonest sign elicited ( $96 \%$ ). Rebound tenderness was seen in $57 \%$ patients.

\section{INTERPRETATION AND CONCLUSION}

Modified Alvarado scoring is a scoring system based on history, clinical examination and a basic laboratory investigation. High scores in males and children were indicative of an inflamed appendix, while in females there was room for other differential diagnosis, as the negative appendectomy rate was $16 \%$. Patients with scores less than 4 did not require subsequent surgery and hence were spared of an unnecessary expenditure. Not all patients with scores between 5 and 6 had inflamed appendix; however, the Negative Appendicectomy Rate (NAR) was found to be lower than the NAR quoted in the surgical literature of $30 \%$ (Hoffmann J, Rausmussen 0) aids in the diagnosis of acute appendicitis BJS 1989;(76):774-90. In females with doubtful diagnosis, additional diagnostic aid like laparoscopy is needed to confirm the diagnosis and accordingly to manage them.

\section{KEYWORDS}

Modified Alvarado Scoring, Appendicitis, RIF Tenderness, Rebound Tenderness.

HOW TO CITE THIS ARTICLE: Kumar PN, Karuppasamy P. Use of modified Alvarado score in the management of acute appendicitis. J. Evolution Med. Dent. Sci. 2016;5(16):801-805, DOI: 10.14260/jemds/2016/185

\section{INTRODUCTION}

For a surgeon confronting a patient with suspected acute appendicitis, the decision to operate or not is not always straightforward, because one has to keep in mind the complications associated with negative appendicectomies and at the same time to prevent missed appendicitis leading to complications.

Financial or Other, Competing Interest: None.

Submission 02-01-2016, Peer Review 07-02-2016,

Acceptance 12-02-2016, Published 25-02-2016.

Corresponding Author:

Dr. P. Naresh Kumar,

$S V M C H \& R C$

Ariyur, Pondicherry.

E-mail:drnk.2011@gmail.com

DOI: $10.14260 /$ jemds/2016/185

\section{Negative Appendicectomy Complications}

1. Wound infection.

2. Incisional hernia.

3. Intestinal obstruction.

4. Sterility (Fimbrial adhesions).

5. Expense.

$\begin{array}{ll}\text { Appendicitis Complications } \\ \text { 1. } & \text { Perforations. } \\ \text { 2. } & \text { Peritonitis Abscess. } \\ \text { 3. } & \text { Peritonitis Generalized. } \\ \text { 4. } & \text { Wound Infection. } \\ \text { 5. } & \text { Tubal Infertility. }\end{array}$

\section{Appendicitis Complications}

1. Perforations

2. Peritonitis Abscess.

4. Wound Infection.

5. Tubal Infertility. 


\begin{tabular}{|c|c|}
\hline Symptoms & Score \\
\hline Migratory right iliac fossa pain & 1 \\
\hline Anorexia & 1 \\
\hline Nausea/Vomiting & 1 \\
\hline Signs & 2 \\
\hline Tenderness in right lower quadrant & 1 \\
\hline Rebound tenderness & 1 \\
\hline Fever greater than 37.5 deg cent & 2 \\
\hline Lab Investigations & $\mathbf{9}$ \\
\hline Leukocytosis greater than & \\
\hline 10,000cells/cn.mm & \\
\hline Total &
\end{tabular}

Thus a number of diagnostic criteria were developed in order to diagnose acute appendicitis accurately in an attempt to bring down the accepted rate of $20-44 \%$ (Hoffmann J, Rasmussen 0, Aids in the diagnosis of appendicitis, BJS, 89 76:774-90) without increasing the morbidity or mortality. One such aid is the Alvarado scoring system, which was subsequently modified by Kalan et al. It is based on 3 symptoms, 3 signs and basic laboratory investigation.

\section{Inference}

\begin{tabular}{|c|c|}
\hline Score & Inference \\
\hline $1-3$ & Appendicitis unlikely \\
\hline $4-6$ & Appendicitis possible \\
\hline $7-8$ & Probable (Take up for surgery) \\
\hline 9 & Definitive (Take up for surgery) \\
\hline
\end{tabular}

- Patients with a score 1 to 3 are considered unlikely to have acute appendicitis.

- Those with a score 4 to 6 are considered to have a possible diagnosis of acute appendicitis, not convincing enough to warrant immediate surgery.

- Patient with scores 7 to 8 are considered to have a probable diagnosis of acute appendicitis and patients with score 9 to have a definitive diagnosis. Both the groups are subjected to surgery.

\section{AIMS AND OBJECTIVES}

The aim of this study is to review the usefulness of modified Alvarado scoring and to evaluate its feasibility as an aid in the surgical decision making of possible appendicitis and in reducing the number of negative appendicectomies.

For this all patients who presented to us with a suspected clinical diagnosis of acute appendicitis were considered for the study. These patients were evaluated by the modified Alvarado score and depending on the score were either operated or observed. The results obtained were studied in relation to the available literature. The accuracy of modified Alvarado scoring system in diagnosing acute appendicitis was assessed.

\section{MATERIALS AND METHODS}

Patients considered for the study were 65 who presented to us between 2014 and 2015 with suspected diagnosis of acute appendicitis by normal clinical assessment, all of whom were evaluated by modified Alvarado score. The total number of patients studied were 65 , of which 39 were males in the age group between 10 and 60 years and 21 were females in the age group between 10 and 60 years and 21 were females in the age group of 10 and 40 years and 6 were children less than 10 years.
The modified Alvarado score a modification of the original Alvarado scoring system (By Kalan et al. Ann R Coll, Surg, Engl, 1994) where the left shift of neutrophil is omitted, as this is not available on a routine basis, is scored against a total of 9. It is based on 3 symptoms, 3 signs and a laboratory investigation. The total score in each case was obtained and depending on the total score obtained patients were either operated or observed. Patients with score 7 to 9 underwent an appendicectomy, while those with a score of less than 7 were not considered for surgery, unless on further observation were thought on clinical grounds to undergo surgery.

\section{OBSERVATION AND RESULTS}

\section{Age and Sex Distribution}

The age group in which acute appendicitis occurred commonly, was between 11 and 30 years. The incidence is less in younger and older age groups with peak incidence in the second and third decades. In this study, males outnumbered females in the ratio of 2:1

\begin{tabular}{|l|c|c|c|}
\hline \hline Age in years & \multicolumn{3}{|c|}{ No. of patients } \\
\hline$<10$ & Males & Females & Total \\
\hline $11-20$ & 5 & 1 & 6 \\
\hline $21-30$ & 18 & 13 & 31 \\
\hline$>30$ & 12 & 5 & 17 \\
\hline
\end{tabular}

\section{Symptom Distribution}

Pain was the commonest presenting symptom and was seen in all patients $(100 \%)$. The classical shifting of pain from umbilicus to right iliac fossa was found in $83 \%$. Next observed were nausea and vomiting $77 \%$ and fever $54 \%$.

\begin{tabular}{|l|c|}
\hline Symptoms & Percentage \\
\hline 1. Pain abdomen & $100 \%$ \\
\hline 2. Anorexia & $57 \%$ \\
\hline 3. Nausea/vomiting & $77 \%$ \\
\hline 4. Constipation/diarrhoea & $3 \%$ \\
\hline 5. Burning micturation & $1 \%$ \\
\hline
\end{tabular}
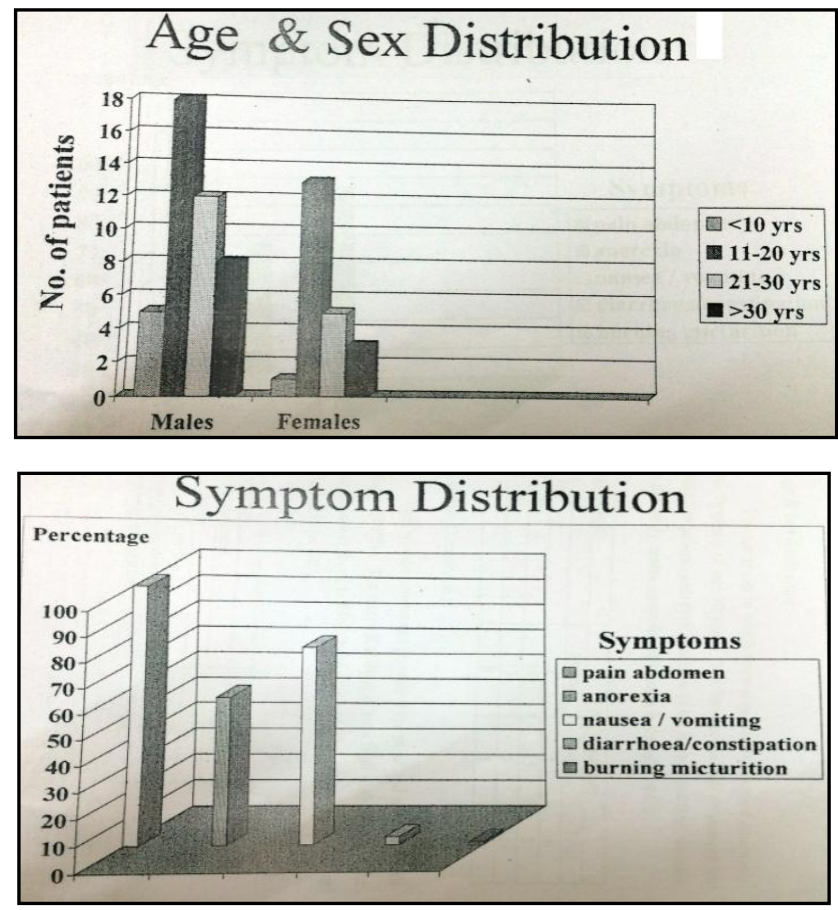

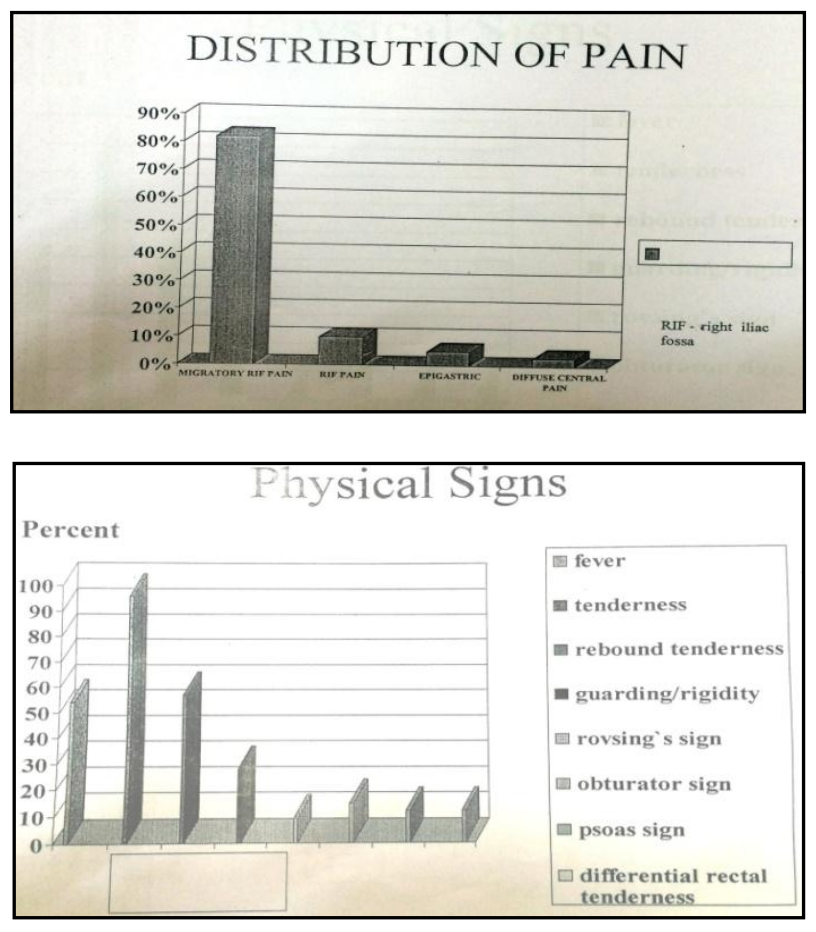

\section{Site of Pain}

\begin{tabular}{|lc|}
\hline Site of Pain & Percentage \\
\hline 1. Migratory pain to RIF & $83 \%$ \\
\hline 2. RIF pain & $10 \%$ \\
\hline 3. Epigastric pain & $4 \%$ \\
\hline 4. Diffuse central abdominal pain & $3 \%$ \\
\hline
\end{tabular}

The commonest site of pain was a central abdominal pain shifting to the right iliac fossa.

\section{Physical Signs}

\begin{tabular}{|llc|}
\hline \multicolumn{1}{|c|}{ Signs } & Percentage \\
\hline 1. & Fever & $54 \%$ \\
\hline 2. & Tenderness & $96 \%$ \\
\hline 3. & Rebound tenderness & $57 \%$ \\
\hline 4. & Guarding / rigidity & $28 \%$ \\
\hline 5. & Rovsing's sign & $9 \%$ \\
\hline 6. & Obturator sign & $15 \%$ \\
\hline 7. & Psoas sign & $12 \%$ \\
\hline 8. & Differential rectal tenderness & $12 \%$ \\
\hline
\end{tabular}

Tenderness at right iliac fossa was the commonest sign elicited followed by rebound tenderness, fever varied between 37.5 deg. and 37.8 deg. cent.

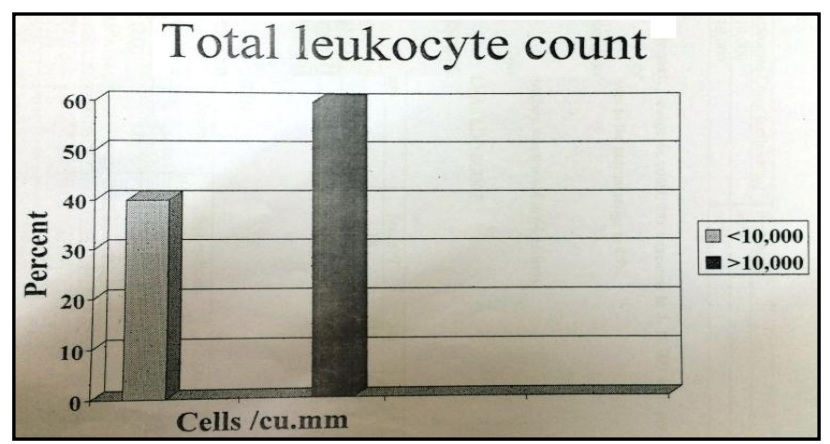

Total Leukocyte Count

\begin{tabular}{|l|l|}
\hline Leukocyte Count (cells/cmm) & Percentage \\
\hline$<10,000$ & $40 \%$ \\
\hline$>10,000$ & $60 \%$ \\
\hline
\end{tabular}

In this study, leukocyte count was increased to $>10,000$ cells per cmm. In $60 \%$ and was in the normal range in $40 \%$ urine microscopy was normal in 64 patients.

\section{Results of Alvarado Score}

\begin{tabular}{|l|c|c|c|}
\hline Total No. of Patients & Score $>7$ & $5-6$ & $<4$ \\
\hline Male (38) & 18 & 15 & 5 \\
\hline Female (21) & 12 & 8 & 1 \\
\hline Children (6) & 6 & - & - \\
\hline
\end{tabular}

\section{Operative Finding}

\begin{tabular}{|l|c|c|c|c|}
\hline Total No. of pts & Score $>7$ & $\begin{array}{c}\text { Appendicitis } \\
\text { (Histopath. Confirmation) }\end{array}$ & $\begin{array}{c}\text { Other } \\
\text { diseases }\end{array}$ & NAR\% \\
\hline Males (38) & 18 & 18 & - & 0 \\
\hline Females (21) & 12 & 10 & 2 & 16 \\
\hline Children (6) & 6 & 6 & - & 0 \\
\hline Males (38) & Score 5-6 & & & \\
\hline Females (21) & 15 & 13 & 2 & 13 \\
\hline Children (6) & - & 5 & 3 & 37 \\
\hline
\end{tabular}

Results of Alvarado Score - Study Conducted by Kalan et al. (Ann R Coll Surg Engl, 1994; 76:418-419)

\begin{tabular}{|l|c|c|c|}
\hline Nos. of Patients & Score $>7$ & $\begin{array}{c}\text { Appendicitis } \\
\text { (histol. Confirmation) }\end{array}$ & NAR \% \\
\hline Men (21) & 15 & 14 & 6 \\
\hline Women (17) & 15 & 10 & 33 \\
\hline Children (11) & 11 & 11 & 0 \\
\hline & Score $<7$ & & 33 \\
\hline Men (21) & 6 & 4 & 50 \\
\hline Women (17) & 2 & 1 & 0 \\
\hline Children (11) & 0 & 0 & \\
\hline
\end{tabular}

Routine blood investigations like hemoglobin, bleeding and clotting time, blood sugars, blood urea and serum creatinine, urine routine like for albumin, sugar and microscopy were done. Patients were prepared. Adequate parenteral fluids and broad spectrum antibiotics were given to maintain fluid balance and afford prophylaxis against wound infection respectively. Temperature, pulse, respiratory rate and urine output chart were maintained. Surgery was done under spinal anaesthesia. McBurney's incision was used when diagnosis was certain and right paramedian was used when diagnosis was in doubt. Preoperatively, the appendix was assessed and removed. When the appendix was found to be normal, other pathology as a cause for the clinical presentation was sought. The appendix was sent for histopathological examination.

Thus a study correlating the on table finding, histology and the clinical presentation in each patient was done. Patients with scores $>7$ were grouped separately, all these patients were subjected to surgery. It was found that patients with score $>7$ were 18 males, 12 females and 6 children. 
All 18 males and 6 children had acute appendicitis confirmed. While only 10 females had acute appendicitis. The negative appendicectomy rate was found to be $16 \%$. One women had ruptured follicular cyst and the other had no finding.

Similarly, patients with score $>7$ were grouped. They were 15 males and 8 females, all subjected to surgery, out of which 13 males and 5 females had acute appendicitis. A Negative Appendicectomy Rate (NAR) of $13 \%$ in males with scores $>7$ and $37 \%$ in females with score $<7$ was obtained. The 8 members with negative appendicectomies had the following finding. Females-two had follicular cysts, one had urinary tract infection. Males-one had mesenteric adenitis, one had no finding; 6 patients had scores $<4$, did not require surgery. All the patients had nonspecific abdominal pain. All the six children had scores $<7$ and all had acute appendicitis confirmed histologically.

\section{Management}

In the 59 patients subjected to surgery, the commonly employed incision was McBurney's incision, which was extended when needed. Right para median was employed when diagnosis was doubtful. Postoperatively, patients were kept nil orally until normal bowel sounds returned; until then were maintained on parenteral fluids, broad-spectrum antibiotics to prevent wound infection. Suture removal was done between the 6th and 8th day.

\begin{tabular}{|lcc|}
\hline \multicolumn{2}{|c|}{ POST OPERATIVE COMPLICATIONS OBSERVED } \\
\hline Post op.complications & No.of patients & percentage \\
\hline 1. Wound infection & 8 & 12 \\
\hline 2. Respiratory tract infection & 6 & 9 \\
\hline 3. Paralytic ileus & 3 & 4 \\
\hline
\end{tabular}

\section{DISCUSSION}

A study of 65 cases of acute appendicitis admitted to SVMCH and RC between 2014-2015 was made, adopting the Kalan's modification of Alvarado scoring system. Acute appendicitis being a common abdominal emergency, still evades the clinician of a straight forward diagnosis even today. In spite of a lot of advances in the diagnostic field-with the invention of sophisticated investigations like ultrasound, CT, NMR, diagnosis of acute appendicitis is not definite.

These investigations are costly, not always available, require specialized services and are time consuming. So even today a thorough clinical examination with basic investigation like WBC count remains the corner stone in the diagnosing of acute appendicitis. This scoring system acts as a clinical aid in diagnosing and managing acute appendicitis.1,2

The symptom commonly found among the patients with acute appendicitis was pain abdomen $(100 \%)$ with a classical shift of pain from umbilicus to RIF (83\%), next observed were nausea and vomiting.

While fever was seen in $54 \%$ of cases, right Iliac fossa tenderness was the commonest sign elicited (96\%), rebound tenderness was seen in $57 \%$. A comparison of the negative appendicectomy rates obtained in our study with the study conducted by Kalan et al. is as follows:

Males and Females with Score $>7$ had a negative appendicectomy rates of $6 \%$ and $33 \%$ respectively (Our study$0 \%$ and $16 \%$ ). In children with scores $>7$ had a negative appendicectomy rates of $6 \%$ and $33 \%$ respectively (Our study
$0 \%$ and $16 \%$ ). In children with scores $>7$ negative appendicectomy rate was $0 \%$ (Our study $-0 \%$ ), whereas in Males and Females with scores $<7$, Nar was 33\% and 50\% respectively (Our study-13\% and 37\%). However, the usefulness of this scorning system is demonstrated by a fall in the accepted rates of $5-22 \%$ in males (In our study it was 6\%) $30-50 \%$ in Females (In our study it was $25 \%$ ) $30-46 \%$ in children (In our study it was 0\%) (Quoted rate taken from Hoffmann J, Rasmussen O. Aids in the diagnosis of acute appendicitis, BJS, 1989;76:774).3,4,5,6,7

In patients with score $>7$, appendicectomy was necessary as the appendix retrieved was found to be inflamed and thus perforation was avoided. In patients with score $<4$, subsequent improvement did not necessitate surgery, thus indicating the usefulness of modified Alvarado scoring system. ${ }^{2}$

In patient with scores between 5-6, observation for 12 24 hours was done and reassessed in the presence of persisting tenderness and high WBC count, appendicectomy was done. The negative appendicectomy rate in males with scores between 5 and 6 was 13\%, while in females of childbearing age group it was high $37 \%$. In this latter group, appendicitis was confused with a lot of other gynaecological conditions like ruptured ovarian cyst, pelvic inflammatory disease, twisted ovarian cyst, etc. Thus a diagnostic tool like laparoscopy may be needed to minimize negative appendicectomy.

In children all had scores $>7$ and all had inflamed appendix. This is important because of the presence of a short omentum, which allows peritonitis to develop early following perforation with its attendant morbidity and mortality. The scoring system is simple to use, easy to apply since it relies on history, clinical examination and a basic laboratory investigation.

\section{SUMMARY}

Modified Alvarado scoring is a scoring system based on history, clinical examination and a basic laboratory investigation. High scores in males and children were indicative of an inflamed appendix, while in females there was room for other differential diagnosis as the negative appendectomy rate was $16 \%$. Patients with scores less than 4 did not require subsequent surgery and hence were spared of an unnecessary expenditure. $8,9,10$

Not all patients with scores between 5 and 6 had inflamed appendix; however, the Negative Appendicectomy Rate (NAR) was found to be lower than the NAR quoted in the surgical literature on $30 \%$ (Hoffmann J, Rasmussen 0) Aids in the diagnosis of acute appendicitis BJS 1989;(76):774-90. In females with doubtful diagnosis, additional diagnostic aids like laparoscopy is needed to confirm the diagnosis and accordingly to manage them. ${ }^{5}$

\section{BIBLIOGRAPHY}

1. Dorai Swamy NV. Leukocyte counts in the diagnosis and prognosis of acute appendicitis in children. BJS 79, Vol. 66, 782-784.

2. Owen TD, Williams H, Stiff G, et al. Evaluation of the Alvarado score in acute appendicitis. JR Soc Med 1992; 85:87-88

3. Alvarado A. A practical score for the early diagnosis of acute appendicitis. Ann Emerg Med 1986; 15(5):557564. 
4. Malik AA, Wani NA. Continuing diagnostic challenge of acute appendicitis, evaluation through modified Alvarado score. Aust N J Surg 1998 July; 68(7):504-505.

5. Macklin CP, Radcliffe GS, Merei JM, et al. A prospective evaluation of modified Alvarado score for acute appendicitis in children. Ann R Coll Surg Engl 1997 May; 79(3):203-205.

6. Brooks DW, JR, MD; Killen DA, MD. Roentgenographic findings in acute appendicitis. Surgery 1963; Vol. 57(3):376-384.

7. Hoffmann J and Rasmussen 0. Aids in the diagnosis of acute appendicitis. BJS 1989 Aug; Vol. 76:774-779.
8. Galindo Gallego M, Fadrique B, Nieto MA, et al. Evaluation of ultrasonographic and clinical diagnostic scoring in suspected appendicitis. BJS 1998; 85:37-40.

9. Michael J Lamparelli, Happy MR Hoque, Caroline J Pogson, et al. A prospective evaluation of the combined use of the modified Alvarado score with selective laparoscopy in adult females in the management of suspected appendicitis. Ann R Coll Surg Engl 2000 May; 82:192-195.

10. Kalam M, Talbot D, Cunliffe WJ, et al. Evaluation of the modified Alvarado score in the diagnosis of acute appendicitis: a prospective study. Ann R Coll Surg Engl 1994; 76:418-419. 